\title{
Por uma etnografia dos cuidados de saúde após a alta hospitalar
}

\author{
Ethnography of health care after hospital discharge
}

Edna A parecida Barbosa de Castro ${ }^{1}$

Kenneth Rochel de Camargo Junior ${ }^{2}$

${ }^{1}$ FaculdadedeEnfermagem, UniversidadeFederal deJuiz deFora. Campus Universitário, M artelos. 36.036-330 Juiz deFora M G.edna.castro@ufjf.edu.br ${ }^{2}$ Instituto de M edicina Social, Universidade Estadual do Rio deJaneiro.
Abstract This paper presents an analysis of how Clifford Geertz' anthropological approach contributes to studies and investigations on health care. Geertz' approach relies basically on a semiotic conception of culture adopting thick description as the axis for interpretive elaborations and defending cultural interpretation as a science allowing to understand processes and to construct knowledge. We will present an overview of some constitutive elements of that author's thoughts we consider relevant for understanding the human experience of dealing with the di sease/health process. The challenging question is how families deal with the need to provide care to a diseased relative after hospital discharge. We use this issue as an excuse for expounding this theoretical approach, interweaving the two areas. The microfocus is the kind of healthcare that takes place outside the cultural environment where the technical forms of care based on scientific knowledge occur. We will briefly discuss how this question becomes evident in an object of study, and how it can be investigated according to the ethnography proposed by Geertz (op. cit.) , allowing, in the end, for some considerations that further contribute to the construction of knowledge in public health. Key words Ethnology, Cultural interpretation, $\mathrm{H}$ ealth care
Resumo Este texto apresenta uma compreensão de como a abordagem antropológica de Clifford Geertz contribui para estudos e investigações sobre o cuidado de saúde. Geertz apóia-se numa concepção de cultura essencialmente semiótica; adota a descrição densa como eixo das elaborações interpretativas, defendendo a interpretação cultural como ciência que possibilita compreender processos e construir conhecimentos. Apre sentaremos uma leitura de elementos constitutivos do pensamento desse autor, que consideramos relevantes à compreensão da experiência humana ao lidar com o processo saúde doença. Do campo da saúde coletiva, a questão que nos desafia é como famílias lidam com a necessidade de praticar cuidados de saúde com um membro doente que demanda cuidados específi cos após uma alta hospitalar. Adotamos como pretexto essa questão para expor essa abordagem teórica, articulando os dois campos. 0 microfoco éo cuidado de saúde que ocorre fora do ambiente cultural em que os cuidados técnicos, rebuscados pelo saber científico, acontecem. Discutiremos brevemente como essa questão se evidencia num objeto de estudo e como ela pode ser investigada segundo a etnografia proposta por Geertz, possibilitando, ao final, considerações que contribuem para a construção do conhecimento no campo da Saúde Coletiva. Palavras-chave Etnologia, Interpretação cultural, Cuidado de saúde 
Introdução

Este artigo apresenta uma leitura da obra de Clifford Geertz, quebusca recolher elementos teóricos que possam servir à produção de estudos relativos ao cuidado da saúde das pessoas, seguida de um relato sumário da análise produzida em uma aplicação concreta deste quadro referencial a uma investigação empírica, no caso a tese de doutorado "A vida após a alta", defendida em dezembro de 2005 no programa de pós-graduação em Saúde Coletiva do Instituto de M edicina Social da UERJ ${ }^{1}$.

Como Michel de Certeau², um historiador que envereda pelo mundo da antropologia cultural para compreender os fenômenos e os processos históricos de nosso tempo, lançamo-nos ao mesmo mundo, acreditando que ele nos possibilitaria compreender al gumas das indefinições existentes no planejamento da oferta de serviços de saúde no Brasil. Convencidos pelo argumento de que convivemos numa sociedade historicamente construída a partir de "culturas", ol hamos para o fenômeno cuidado de saúde também no plural. Cuidados, numa dimensão cultural, significarão, portanto, neste texto, cuidados segundo "culturas" de cuidar.

Debruçar-nos-emos sobre um pensamento que acreditamos contribuir para uma abordagem metodológica, quando o objeto écompreender fenômenos que se encontram no âmbito das relações entre sujeitos que necessitam de cuidados eos que cuidam (institucionalmenteou não). Em específico, a compreensão do "cuidado praticado pela família" como um fenômeno quese expressa na forma de uma cultura de cuidar no interior das relações entre pessoas, na dinâmica do viver e, acrescenta-se, do viver em sociedades urbanizadas. E considerando, ainda, a convivência dos sujeitos com um sistema de saúde ecom uma cultura institucionalizada de cuidados de saúde.

0 ol har que pretendemos primeiro é para a "família que cuida", como base para a análise da relação entre família e a necessidade de cuidados no domicílio, a partir de cenários culturais orientados por um cotidiano. N estetexto, ao nos referirmos ao termo cotidiano, consideraremos a compreensão que Pinheiro ${ }^{3}$, de dentro do campo da Saúde Coletiva, defende. Essa autora se refere a este como sendo o lócus onde se expressam não somente as experiências de vida na perspectiva individual que o termo cotidiano possa sugerir, mas os contextos de relações distintas que envolvem tanto pessoas, como col etividades e instituições em espaços e tempos determinados.
Destacamos, ainda, que, do lugar onde nos encontramos, ena compreensão de lugar defendida por Certeau ${ }^{2}$, assumimos os riscos de produzir um discurso particularizado. A intenção, todavia, é provocar uma discussão que explicite limites, articulando o campo da Saúde Coletiva com outro, o da antropologia. E o navegar nessas"duas grandes águas" (metáfora adotada pelo antropólogo O ctávio Bonnet ${ }^{4}$ ao referir-se à articulação aqui proposta) permite apresentar uma compreensão de como a interpretação cultural defendida pelo antropólogo Clifford Geertz ${ }^{5-8}$ pode contribuir para estudos e investigações sobre cuidados de saúde no campo da Saúde Coletiva.

Em especial, tomando como foco de análise o processo de investigação sobre o "cuidado pela família" em estudos da vida após a alta hospitalar, sem a intenção de apresentar aqui os achados com seu corpo de evidências.

A vida após a alta: delimitando o problema

Uma notada indefinição na prática da assistência à saúde sobre quem é o responsável pelos cuidados de que uma pessoa passa a depender após uma internação hospitalar por uma doença grave reveste-se num problema de natureza assistencial no atual contexto da oferta deserviços do SistemaÚ nico deSaúdebrasileiro. 0 dilema está na existência de necessidade de cuidados especializados, demandados por cidadãos usuários do SUS em sua trajetória após uma alta hospitalar, que não se encontram incluídos no conjunto de atividades rotineiramente ofertadas pelas equipes de saúde da família e nem tampouco no das equipes de especialistas no interior dos hospitais.

Quais são os eventos que se constroem no âmbito da família em suas relações e na convivência com um membro doentee com a "obrigação", "responsabilidade" ou "compromisso" de cuidar? Como estas relações se dão, bem como 0 processo de gestão do cuidado por parte dela frente às diversas situações postas pelo cotidiano, em seu contexto cultural mais restrito, sem perder de vista a sua inserção em contextos culturais globalizadores?

No contexto da vida após a alta hospitalar por tratamentos de grande complexidade, cirurgias ou tratamentos intensivos, é possível acreditar que a família usuária do SUS dará conta de assimilar conhecimentos específicos aos cuidados, de praticá-los para prosseguir dando o alívio de que seus membros necessitam diante da doença ou do tratamento? É possível acreditar 
que o sistema público de saúde, através de suas autoridades e planejadores, conseguirá absorver, resolver ou ao menos dar uma resposta a esse problema, com suas políticas e estratégias, apoiando-se, sobretudo, na premissa constitucional de que "saúde é um direito de todos e dever do Estado"?

Parecem existir lacunas assistenciais entreum e outro nível de atenção, tal como vem se consolidando a organização da atenção apoiada na diretriz de hierarquização.

\section{O delineamento do estudo}

Preliminarmenteà observação etnográfica, constituímos uma amostra de 137 pacientes internados numa UTI tipo II, de um hospital público, no segundo semestre de 2003. Destes, 66 tiveram alta hospitalar e, entre os últimos, 36 ficaram totalmente dependentes de cuidados em casa. Todos eles demandariam acompanhamento por equipe de saúde, após a alta hospitalar, uma vez que o seu estado de saúde no momento da alta era considerado "melhorado". Eram seres humanos adultos ou idosos que ficariam "dependentes" de cuidados básicos para a vida e/ou de procedimentos especializados, como sondagens, irrigações, curativos, oxigenoterapia, entreoutros.

Adotando a etnografia como metodologia, aproximamo-nos de doze famílias buscando compreender como estas lidavam com a necessidade de realizar cuidados após a alta hospitalar em um dos membros doente. Observamos de modo sistemático seis destas famílias e uma se evidenciou como o "grande caso" para a análise que se segue. As famílias, residentes na cidade de Juiz de Fora, compartilham de uma mesma cultura assistencial e são submetidas a um mesmo padrão de organização e de fluxo de atendimento no sistema de saúdelocal. 0 ambientemicroscópico, preferencial da pesquisa era 0 ambiente onde o paciente residia com sua família.

Esta etnografia da vida após a alta hospitalar permitiu-nos apreender e analisar que, quando a família recebea grandecargaemocional de "ter que cuidar", quando é tomada de modo abrupto por aquela "chegada de hora", sem prenúncios, a resposta emocional sobrepuja as de expediente prático, modificando-se, posteriormente, tais reações.

A preendemos respostas como essas ao acompanhar, desde a internação, a trajetória de uma mulher de 53 anos, usuária do SUS, de família considerada de "baixa renda", internada por um segundo Acidente Vascular Encefálico (AVE). A mesma saiu de alta hospitalar com a sonda nasoentérica, para alimentação, usando fraldas, pois ficara com incontinência urinária e fecal e, ainda, dependentede uma cadeira derodas. Todo o lado esquerdo de seu corpo não se movia (hemiplegia à esquerda), também não deglutia os alimentos com segurança e se comunicava com gestos e murmúrios. Por um período de quatro meses após a alta, ela permaneceu com a mesma sonda, sujeita a el evados riscos de vida. Recebia cuidados contínuos por uma sobrinha de 27 anos, solteira, mãe de três filhos pequenos (um amamentando), que cursara até a sétima série do ensino fundamental, contratada pela família nuclear para essa função.

A observação contínua, por um período de dois anos, do cotidiano dessa paciente junto a sua família mostrou o descaso, a desconsideração ea falta de compromisso por parte dos agentes do sistema em lidar com o conjunto denecessidades de cuidados especializados que manifestava. Para além de uma questão de habilidades e de competências dos profissionais de saúde, estamos, antes, diante de uma imperiosa necessidade de definição: até onde vai a responsabilidade das equipes de saúde envolvidas, considerando-se 0 atual fluxo hierarquizado das ações de saúde? Q uem, entreos níveis de aten ção, deveser a principal referência, ou a de melhor resolutividade para o usuário nessas condições?

Outra família observada ao longo da pesquisa de campo evidenciou a convivência com as complicações de uma cirrose hepática. O bservamos que o ser humano que convive com uma doença grave, como, por exemplo, a total perda de função do fígado, secundariamentea uma cirrose hepática causada pelo al coolismo, por vezes se sente como um moribundo nas fases de agudização pelo déficit da função hepática. $E$, do ponto de vista daquele que vivia o adoecimento, notava-se certo silêncio ao se falar da doença, evitando-se prenunciar um futuro, um sentido para a sua vida.

As hemorragias digestivas, complicação recorrentenessetipo deadoecimento hepático, por causa de varizes quesurgem no esôfago, são consideradas emergenciais e colocam a vida em risco. A convivência com esse risco leva a família e o próprio doente a desejarem um vínculo "fácil" com um serviço de saúde que lhes compreenda as angústias e que lhes dê segurança de que 0 doente "viverá" por ter um atendimento rápido e preciso. É o viver que está por detrás da luta por condições detratamento. Não somente das ameaçadoras hemorragias, mas do medicamento caro 
que garanta um dia a mais, além da necessidade de um transplante de fígado.

O estar numa fila de transplante já angaria alguma esperança, mas a agilidade para o "andar" da fila vai sendo buscada e, por vezes, com empenho, através de convivência com políticos, com médicos ou pessoas influentes no interior do sistema de saúde. Ainda que organizadas por legislações claras e submetidas a constantes fiscal izações, sobretudo pela soci edade civil organizada, as tentativas ocorrem e vão dando sentido à vida.

0 sentimento de abandono fica-nos evidente ao confrontar o cotidiano dessas pessoas com as instituições sociais preconizadas para resolvê-lo. No interior do sistema público de saúde, o fluxo do usuário, regido pelas políticas nacionais e locais, vem sendo ordenado sistematicamente, conforme as agudizações ou agravos de doenças. As pessoas dependentes do SUS não estão mais livres a procurar "o seu médico" ou seu serviço de saúde, mas estão sujeitas a uma trajetória orientadora peculiar ao atendimento, que pode ser demorado demais para as pessoas e nem sempre garantir que chegará ao ambienteonde haja maior vínculo entre os sujeitos envolvidos ou que garanta ao interessado no cuidado a segurança de os profissionais reconhecerem o seu problema de saúde e, portanto, agi rem com rapidez.

Abordagem interpretativa das culturas de cuidados de saúde após a alta hospitalar

O foco central desta seção é apresentar como o pensamento de Clifford Geertz ${ }^{5-8}$ pode ser adotado para compreendermos questões próprias do campo da Saúde Coletiva, como as apontadas acima. Referimo-nos à teoria interpretativa da cultura defendida por esse autor.

Não será possível aqui, mas em outras oportunidades, o aprofundamento em aspectos conceituais que a questão como um todo requer $\mathrm{e}$ merece, como, por exemplo, sobre família e sobre cuidado. Entretanto, é a dimensão cultural do cuidado de saúde queé praticado por pessoas queconvivem demodo significativo em ambiente familiar que buscaremos enfocar enquanto pretexto para apresentar um olhar, um pensamento antropológico que possibilita à etnografia o "status" de uma ciência inter pretativa.

Geertz ${ }^{5}$ desenvolveu seu pensamento sobre interpretação cultural, assumindo uma compreensão essencialmente semiótica de cultura, originária do pensamento weberiano, segundo o qual "o homem é um animal amarrado a teias de significados que ele mesmo teceu". A cultura passa, então, a ser para el e essas teias, cuja análise e cuja interpretação permitem uma ciência interpretativaà procurado significado, em vez deumaciência experimental em busca de leis. Distancia-se das ciências explicativas quando propõe 0 afunilamento das questões de estudo, a microscopia e o aprofundamento nalgum ponto pouco esclarecido. Nas palavras de Geertz' " "é justamente uma explicação que se procura ao construir expressões sociais enigmáticas na sua superfície. Todavia, essa afirmativa, uma doutrina numa cláusula, por si mesma, requer uma explicação".

Teceu seu argumento de defesa da interpretação cultural como possibilidade de se "fazer ciência", a partir da elaboração de uma análise crítica e comparativa ao pensamento científico predominante, defendido pelas ciências naturais. Partiu do pressuposto de que as leis resultantes de teorias científicas não explicam tudo, em especial 0 que é humano. Devemos, portanto, "isolar" justamenteaquilo queas ciências naturaisnão explicam; algo que esteja no bojo das relações humanas e cuja investigação e compreensão sejam favorecidas pela interpretação cultural. I sso significa identificar o que, certamente, não se poderia transformar em leis pelo pensamento científico tradicional, uma vez que os praticantes das ciências naturais investem em reduzir fenômenos eminentemente humanos ao mesmo fluxo de comportamento de seus objetos inanimados ou irracionais, ou, ainda, a modelos matemáticos.

O "isolar" o cuidado em saúde, como fenômeno de estudo, nesse viés de pensamento, pressupõe, primeiro, queadmitamos que essa seja uma prática eminentemente humana, realizada entre pessoas. Sendo assim, são dois os lugares com saberes, vocações e culturas distintas: um, o lugar da pessoa que sofre e que requer os cuidados e outro, o daquela que produz equeaplica o cuidado de saúde na forma de ações direcionadas ao que dele necessita. Essas ações, concebidas e elaboradas por um processo mental, se exteriorizam econcretizam através de ações num contexto e com capacidade de alterações no conjunto de necessidades do outro. Costumeiramente, denominamos de cuidado de saúde ações que provocam respostas de alívio ou sensação de conforto e segurança em uma pessoa, secundariamente à intervenção física ou subjetiva previamente planejada e aplicada por outra. 0 cuidado revertido em ações podepermitir gradações para uma maior ou menor satisfação de necessidades.

Existe, portanto, um processo de pensamen- 
to; de um lado, o dos profissionais de saúde, que se esforçam em identificar em seres humanos, e em contextos culturalmente definidos, suas necessidades, acumulando informações sobre elas, que se associam aos seus saberes sobre cuidados, permitindo uma organização mental acerca de formas de exteriorizar as tomadas de decisão. $\mathrm{Nem}$ sempre o foco é para a pessoa que tem as necessidades, mas para as necessidades em si, descoladas de um contexto de vida. Cuidados, como uma prática extraída da relação entre humanos, somente poderão ser compreendidos se, antes, localizarmos os ambientes de vivência ede convivência destas pessoas. Compreendê-los na dinâmica da vida, culturalmente concebidos e praticados por um membro da família a um outro doente, pode ser possível a partir da interpretação dos processos de construção mental de tais ações, como também do processo que culmina com as necessidades especificamente destas e não de outras ações.

Dificilmente conseguiremos compreender necessidades humanas a partir de metodologias quetentam, por exemplo, medi-las, tipificá-las e defini-las com exatidão através de características, manifestações ou expressão de um grupo de sujeitos de um dado contexto cultural ou sociedade, com a finalidade de generalizá-las para outros sujeitos, sejam eles de quaisquer contextos culturais ou sociais.

É possível que, nalgum momento da vida, os seres humanos necessitem de cuidados de outros, como uma lei do cuidado em saúde, sobretudo quando consideramos que o cuidado extrapola a saúde, destacando seu antagônico, a doença. N este caso, o cuidado será para a vida. Então, crianças e idosos podem estar incluídos, como extremos de começo e final da vida, como gruposhumanos quenecessitarão inevitavelmente decuidados deoutros. 0 tipo eforma de encarar o cuidado emanado équenão pode ser generalizado de uma cultura para outra. No mínimo, alguma adaptação terá que ser feita.

Outra assertiva universal poderia ser a deque todo ser humano tem potencial para cuidar desi e de outros, como defendeu Leininger ${ }^{9}$. Entretanto, "o como" secuida desi edeoutros, ou seja, o processo de cuidado não poderá ser generalizado de uma cultura para outra. Concordamos que existem aspectos comuns euniversais no que tange à necessidade e à prática de cuidados entre humanos, coexistindo, todavia, com uma diversidade de "modos de cuidar" que parecem estar em consonância com a diversidade cultural.

Ao nos referirmos ao pensamento de Leinin- ger ${ }^{9}$ sobre o cuidado de enfermagem, na dimensão transcultural defendida por ela, a intenção não é generalizar particularidades ou formas de cuidados e nem de defender queisso seja possível ou não, mas de reconhecer que se trata de um fenômeno eminentemente humano, produzido pelos homens em suas relações entre si e com 0 mundo. Significa compreender que o homem, por natureza, tem potencial para o "cuidar de si" e o "cuidar de outros", e o cuidado segue pelas gerações transcultural euniversalmente, mas sem descartar a diversidade cultural que contribui para a presente elucidação sobre aspectos pontuais. O cuidado é, portanto, significativo ao homem. Cuidado para a vida. E, se um cuidado de natureza cultural, podeentão ser interpretado a partir das teias de significados tecidas pelo homem que cuida e pelo que recebeo cuidado. Pode ser interpretado, sobretudo, em momentos de maior fragilidadeem seus contextos devida, quando este se especializa, tornando-se um cuidado técnico e decorrente das manifestações do corpo mediante uma doença ou tratamento próprio do setor de saúde.

Quando é esse cuidar específico que nós buscamos compreender, um cuidar que resulta do homem em suas relações sociais, dificilmente 0 conseguimos através de metodologias estruturadas, que, antes de interpretar os significados de cada fio de uma teia culturalmente tecida pelo homem quecuida, consideram o cuidado especializado como um objeto cognoscível, possível de ser identificado ou definido a partir de fórmulas ou operações matemáticas. A idéia não é negar 0 valor de evidências vindas de tais modelos que subsidiam intervenções clínicas, por exemplo, mas é alertar que não devem ser a "máxima do cuidado" e a referência única no campo das práticas das profissões de saúde.

Para Geertz ${ }^{5}$, o operacionismo como dogma metodológico nunca fez muito sentido no que concerne às ciências sociais e, a não ser por alguns cantos, já bem varridos - "o behaviorismo" skinneriano, os testes de inteligência, etc. estão, agora, praticamente mortos. Segundo ele, se quisermos compreender o que é a ciência, devemos olhar, primeiro, não para suas teorias ou as suas descobertas, e, certamente, não para o que seus apologistas dizem sobre ela, e sim precisamos ver 0 que os praticantes da ciência fazem.

É etnografia o quea antropologia social faze, no caso, consideramos como uma prática adequada para se compreender o cuidado que vai sendo tecido pela família ao cuidar de um membro que, de súbito, passa a demandar cuidados 
em casa. E é justamente quando se compreende o queéa etnografia, ou mais exatamente, o queé a sua prática, éque se pode começar a entender 0 que representa a análiseantropológica como forma de conhecimento. 0 objeto da etnografia advém de uma hierarquia estratificada de estruturas significantes. N os escritos etnográficos acabados, o que chamamos de "nossos dados" é realmente, como diz Geertz", "a nossa própria construção": [...] das construções de outras pessoas, do que elas e seus compatriotas se propõem está obscurecido, pois a maior parte do que precisamos para compreender um acontecimento particular, um ritual, uma idéia ou o que quer que seja, está insinuando como informação de fundo antes da coisa em si mesma ser examinada diretamente. [...] Bem no fundo da base factual a rocha dura, se éque existe uma, de todo empreendimento, nós já estamos explicando e, o que é pior, explicando explicações. [...] A tarefa soa muito parecida com a tarefa deum decifrador de códigos, quando, na verdade, ela émuito parecida com a do crítico literário - e determinar sua base social e sua importância.

A análise em etnografia representa a ação de escolher entre as estruturas de significação (códigos estabelecidos ou as expressões mistificadas quepossam ser decodificadas) determinando sua base social e sua importância no contexto da investigação. Quadros desiguais de interpretação relacionados ao mundo dos diferentes sujeitos podem surgir e devem ser explicitados no texto, evidenciando-se a relação existente entre eles e que sentido fazem no sentido global da questão em análise.

0 que o etnógrafo enfrenta, de fato (a não ser quando está seguindo as rotinas mais automatizadas de coletar os dados), é uma multiplicidade de estruturas conceituais complexas, muitas delas sobrepostas ou amarradas umas as outras. Isso significa, primeiro, apreender; depois, interpretar e, por último, apresentar.

Com isso, queremos dizer que o desafio assumido pela etnografia não se reduz a um conjunto de técnicas, nem aos processos que a definem enquanto método de investigação eque são determinados e expressos nos livros-texto. Não se reduz a uma lista de procedimentos, como, por exemplo, estabelecer relações; selecionar informantes; transcrever textos; levantar genealogias; mapear campos ou manter um diário. Sem a intenção de banalizá-las no âmbito do processo investigativo, queremos frisar que o que defineo método antropológico, para além das ferramentas adotadas pelo etnógrafo, é o tipo de es- forço intelectual que ele representa. $N$ as palavras de Geertz', "um risco elaborado para uma descrição densa".

A etnografia é, nesse viés de pensamento, uma descrição densa. Geertz ${ }^{5}$ adota a noção de descrição densa deGilbert Ryle, a partir de dois en saios daquele autor, dos quais se abstrai a idéia, ou constructo teórico, da descrição densa. Um deles, o ensaio sobre as piscadelas iniciadas por um garoto que queria imitar outro que piscava. Ryle prossegue decodificando e esclarece que o primeiro garoto pisca por um tique nervoso, o segundo pisca para imitá-lo, daí depreende-se a intencionalidadedo imitar. E prossegueacrescentando que um terceiro garoto pisca para outro, como o primeiro, porém de modo conspiratório (um código cultural) eassim por diante. Ao descrever as diversas possibilidades de piscadel as dos garotos, ele quer evidenciar pelo menos dois aspectos: um éa existência dos significados e outro é o potencial do observador humano de interpretar. Isso dá o caráter de densidade à descrição, diferenciando de um relatório puramente descritivo, que exclui a interpretação humana e sefixa em variáveis como, por exemplo, o número de movimentos dos ol hos que se repetem; os músculos envolvidos, etc., e, para isso, bastarse-ia analisar uma filmagem.

Nas palavras do próprio Geertz ${ }^{5}$, a exigência de atenção de um relatório etnográfico não repousa tanto na capacidade do autor em captar os fatos primitivos em lugares distantes elevá- los para casa como uma máscara ou um entalho, mas no grau em que ele é capaz de esclarecer o que ocorre em tais lugares, para reduzir a perplexidade. Isso significa dizer que poderemos encontrar outros problemas, queinicialmentenão nos ocorreram, cabendo-nos contínuas "avaliações" durante 0 trabalho de campo. E prossegue dizendo: Se a etnografia é uma descrição densa e os etnógrafos são os que fazem a descrição, então a questão determinante para qualquer exemplo dado, seja um diário de campo sarcástico ou uma monografia alentada do tipo Malinowski, é se ela separa as piscadelas dos tiques nervosos e as piscadelas verdadeiras das imitadas.

Uma descrição densa não necessariamente se referea um texto longo eprolixo, mas a um texto que apresenta as evidências prenhes de significados que permitiram ao observador interpretar os sentidos que fazem num dado contexto cultural, emitindo suas asserções que possibilitam a ele e a outros compreender uma dada questão. As evidências são os dados brutos extraídos do campo (partes das notas de observações, falas 
ou outros artefatos colhidos no campo). Tornam-se evidências exatamente quando seguidas da interpretação na qual agregamos os significados apreendidos da cultura corrente, permitindo elaborações de asserções acerca do fenômeno a quesereferem. A densidade também se relaciona à experiência do investigador.

N este caso, a tradição de sermos enfermeiros ou médicos com uma história de vida profissional na área da saúde, de relações sociais e de formação acadêmica na área das ciências humanas, enfim, de leituras sobre o objeto em observação, será a experiência que nos permitirá apreender os sinais prenhes de significados a serem interpretados à luz de um contexto de vida e de cuidados de saúde, e, posteriormente, professados na forma de descrição.

Numa teorização do cuidado a partir da sua prática pela família mediante uma situação de agravo à saúde, o comportamento humano vai sendo visto como uma ação simbólica, na qual a intenção de cuidar e o como se cuida do outro, que lhe é significativo, vão sendo apreendidos. Todavia, a questão sobre a qual nos debruçamos ao querer estudar os comportamentos humanos decuidado éque deve estar clara, com o grau de importância que the asseguramos: para que queremos saber isso?

D ois são os cuidados que devemos ter ao perseguirmos tal compreensão, tomando a cultura como possibilidade de interpretação do comportamento humano de cuidado, como pontua $\mathrm{Ge}$ ertz : primeiro, ao imaginarmos que a cultura é uma realidade superorgânica, autocontida, com forças e propósitos em si mesma, poderíamos "reificá-la"; segundo, se nos satisfazemos com a idéia de queela consisteno padrão bruto deacontecimentos comportamentais que de fato observamos ocorrer em uma ou outra comunidade identificável, isso significa reduzi-la.

Com isso, ter cuidado para não a reificar ou reduzir significa que não devemos considerar ou nos apoiarmos na idéia de que exista um local específico para a localização da cultura. Geertz ${ }^{5}$ defendea idéia dequea cultura não está localizada nem na mente nem no coração dos homens, podendo estar em qualquer outro lugar fora do corpo.

Assim, ao tomarmos as culturas humanas como objeto de estudo, devemos evitar o subjetivismo extremo associado a um objetivismo também extremo. Aliás, juntos ou separados, subjetivismo e objetivismo quando adotados de modo extremados podem levar a uma explosão de análises particulares, que surgem sob a forma de ta- xonomias, paradigmas, tabelas, genealogias, etc., comprometendo a interpretação cultural.

Em nosso caso, devemos estar atentos se, no estudo do cuidado, aquilo que estamos interpretando reflete o que os membros das famílias fazem esefazem demodo consciente, quando prestam o cuidado em casa; se o que evidenciam, na forma de falas, comportamentos, enfim, de respostas humanas, representa o que sentem e pensam "realmente" acerca do que fazem, ou se representam, como pontua Geertz" , "apenas simulações inteligentes, equival entes lógicos, mas substantivamente diferentes do que el es pensam".

Ao fazermos uma interpretação, devemos le var em consideração a origem social e cultural das pessoas e como relatam o seu modo de viver antes e após o adoecimento, ou seja, a noção que têm de seu próprio corpo e a relação deste com a vida. Se, ao narrarmos os discursos de nossos sujeitos, ou ao descrevermos os significados extraídos de seus contextos, adotarmos uma construção de representações impecáveis, de ordem formal, mas cuja existência verdadeira praticamente ninguém pode acreditar, corremos o risco de estar contribuindo para o descrédito da análise cultural, além de falsearmos uma prática e em muito pouco contribuir para o avanço do estudo e da prática do cuidado de saúde. N esta concepção, parafraseando Geertz ${ }^{5}$, uma boa interpretação, de qualquer coisa - um poema, uma pessoa, uma história, um ritual, uma instituição, uma sociedade - leva-nos ao cerne do que estamos propondo interpretar. Quando isso não ocorre, nos conduz ao contrário, a al go diferente.

Devemos estar atentos se, no cotidiano observado, as pessoas simulam comportamentos para ser aprovadas pelo padrão cultural, enquanto seus pensamentos não conferem com o padrão cultural corrente; para que não interpretemos outra coisa diferente daquilo que realmente está acontecen do naquele contexto que estamos estudando. $\mathrm{N}$ em sempre as respostas fornecidas formalmente ou através dos discursos dos sujeitos, emanados de um processo de pensamento em torno de uma questão, serão fidedignas a uma cultura se descoladas de uma estrutura de significados estabelecidos social mente. Aí está o valor da observação etnográfica.

Para Geertz $z^{5}$, "a cultura consiste em estruturas de significados social mente estabelecidos nos termos dos quais, [por exemplo], as pessoas fazem certas coisas, como sinais de conspiração e sealienam ou percebem os insultos e respondem a eles". E isso, nesta visão, não é mais do que dizer que "esseé um fenômeno psicológico, uma 
característica da mente, da personalidade, da estrutura cognitiva de alguém". 0 desafio passa a ser o de "tentar formular a base na qual se imagina, sempre excessivamente, estar-se situado. Eis no que consiste o texto antropológico como empreendimento científico".

Podemos considerar que existe um contexto cultural de cuidados no âmbito do SUS; uma estrutura de significados que vem sendo estabelecida ao longo de sua implantação. As condições que definem o acesso aos serviços de saúde podem influenciar nas respostas enos movimentos de busca de cuidados pelos seus usuários. Como exemplos, temos o comportamento que umas pessoas exibem nos serviços com o fim de obter a resolução de seus problemas de saúde, de necessidade de cuidados ou, ainda, os conflitos que expõem a um profissional ou às equipes de saúde. Conceber, entretanto, que tais simulações acontecem significa admitir queesses sujeitos que as exibem reconhecem a existência de uma conjuntura de cuidados de saúde, da tal cultura em torno da oferta dos serviços. Para outras pessoas, todavia, o comportamento de busca de cuidados pode ser o de nem buscar, numa manifestação de completa ausência de noção da existência seja do serviço seja do seu direito a ele. E assim por diante. A empreitada etnográfica está em, ao identificar tais comportamentos, decodificar a teia de significados na qual se tecem.

$\mathrm{Na}$ concepção de $\mathrm{Clifford}^{10}$, um valor de investigações etnográficas inter pretativas está, principalmente, na origem e tipo de dado encontrado (histórias, conversas, eventos, por exemplo) e na forma em que tais achados são apresentados, adotando alegorias, próprias de um estilo literário, para interpretá-los. "Qualquer história tem uma propensão a gerar outra história na mente do leitor (ou ouvinte), a repetir edeslocar alguma história anterior". Entretanto, para que se produza esse efeito, o texto deve ser cuidadosamente tratado. Podemos utilizar as "alegorias" ou a técnica da narrativa, que permite, seja no "falar do outro", seja no falar de um padrão de idéias ou eventos, uma espontaneidade artística, de natureza, por vezes, até poética, que "quebra" o caráter unicamente descritivo, rígido e formal, típico da escrita dos textos técnicos da saúde. Acrescenta-nos Clifford ${ }^{10}$, que [...] o trabalho de campo antropológico tem sido representado tanto como um "laboratório" científico quanto como um "rito de passagem" pessoal. As duas metáforas captam precisamente a impossível tentativa da disciplina em fundir práticas objetivas e subjetivas. Até recentemente, a impossibilidadeera mascarada pela marginalização dos fundamentos intersubjetivos do trabalho de campo, pela sua exclusão dos textos etnográficos sérios, rel egando- os aos prefácios, me mórias, anedotas, confissões e assim por diante. Posteriormente, o conjunto de regras disciplinares foi sendo substituído.

James Clifford ${ }^{10}$ considera que a nova tendência de nomear e citar os informantes de forma mais completa edeintroduzir el ementos pessoais no texto está alterando a estratégia discursiva da etnografia e seu modo de autoridade, ampliando-a. 0 valor das evidências etnográficas relaciona-se, diretamente, com "o estar lá" do pesquisador. 0 estar "dentro" do mundo dos sujeitos. E esse estar lá consideramos uma importanteforma de participação ten do em vista o tal "rito de passagem pessoal". O processo de reflexão permite transformações em ambos os mundos: 0 dos sujeitos e 0 do investigador.

Uma consideração acerca de al guns estudose pesquisas em saúde realizadas à luz dos conhecimentos originados no campo das ciências sociais e humanas é que nem sempre encontram uma forma de comunicação que permita aos sujeitos envolvidos numa determinada prática da saúde compreender os processos estudados, contribuindo pouco com os processos de mudança. U ma crítica se relaciona aos textos rebuscados, em linguagem por vezes incompreensível, dificultando 0 acesso aos "produtos da ciência", alargando 0 "abismo" notado entre aqueles que "produzem" as teorias sobre o cuidado e aqueles que "consomem" um trabalho acadêmico, ou seja, os que cotidianamente executam o cuidado de saúde.

A linguagem, dentre outras, torna-se uma ferramenta fundamental e M erleau-Ponty ${ }^{11}$, ao discorrer sobre a experiência da expressão em sua relação com a ciência, diz que a virtude da linguagem é lançar-nos sobre o que ela significa. 0 trecho a seguir, dito por M erleau-Ponty ${ }^{11}$, evidencia, justamente, aquela que parece ser a principal contribuição deum relatório que sepropõe à interpretação de cenários culturais dados no campo da Saúde Coletiva: Ora, é de fato um resultado da linguagem fazer-se esquecer ao conseguir exprimir. À medida que sou cativado por um livro, não vejo mais as letras na página, não sei mais quando virei a página. [...] Quando alguém - autor ou amigo - soube exprimir-se, os signos são imediatamente esquecidos, só permaneceo sentido, e a perfei ção da linguagem é, de fato, passar despercebida.

Numa leitura prazerosa, em que captamos os sentidos dos acontecimentos narrados, estes se instalam em nossa memória, permitindo-nos 
o envolvimento tão logo nos coloquemos diante de tais acontecimentos.

A prática de interpretação cultural em Saúde Coletiva, resultante de um trabalho de campo etnográfico, contribui, por exemplo, para se descrever a experiência humana que se desenvolve ao lidar com o processo saúde-doença, explicitando os significados que se estabel ecem em torno deste, permitindo a outros vivenciarem, ou experimentarem, de modo semel hante, o queessa lida representa para aqueles sujeitos.

O lidar de pessoas com agravos à saúde e de suas famílias após a alta hospitalar com a necessidade decuidados passa, momentaneamente, de um fenômeno dinâmico, em processo contínuo, a objeto de aten ção e estudo, na medida em que - que se busca éuma compreen são microscópica do cuidado aí praticado. Entretanto, a decodificação de linguagem, ou o achado designificados, requer árduos investimentos eenvolvimento pessoal aprofundado no mundo dos sujeitos ou cenários que se quer interpretar. A missão mais árdua, talvez, esteja no conversar com as famílias que cuidam de um membro doente ou em situação que requer cuidados humanos ou técnicos, edepois al argar o discurso delas para outros grupos que cuidam institucionalmente ou não. No conjunto do empreendimento etnográfico, esse parece ser o que apresenta maior grau de dificuldade. A experiência acumulada parece influenciar a entrada, permanência e saída do campo de observação.

Geertz ${ }^{5}$ assume um pressuposto de que o falar por alguém parece ser um processo misterioso. Isso pode ser devido ao fato de que falar a alguém não parece, definitivamente, misterioso na lida cotidiana. 0 quenatural mente edemodo predominante fazemos, como profissionais, ao praticarmos o cuidado de saúde no interior de instituições, éemitir para as pessoas o que devem fazer; como devem se cuidar.

Entretanto, estamos de um lado em que a cultura de cuidado vai sendo instituída sob influência dos saberes e comportamentos institucionalizados etidos como científicos. O sair do lugar, no qual também somos cuidadores, e ir ao mundo do sujeito que pressupomos se autocuidar, para compreender a sua cultura de cuidar, muito mais do que simplesmente lhe falar, ofere ce riscos e limites. 0 grande limite parece estar entre a dificuldade que isso representa e o risco de que o nosso saber oriente 0 tal discurso que procuramos.

O risco começa já no encontro com essas famílias, porque não é o mesmo que ir para um outro lugar, uma aldeia distante, por exemplo, cujos costumes e cultura são-nos completamente estranhos. Como, por exemplo, Geertz ${ }^{5-8}$, cidadão norte-americano, foi a Bali elá identificou e estudou os significados das rinhas ou "brigas de galos" na vida dos balineses. Estamos ambos, famílias que cuidam e profissionais que cuidamos, mergulhados numa mesma cultura brasileira e, ainda, ao que acrescenta Certeau ${ }^{2}$, numa convivência com uma contracultura eseparados, pelo que Gilberto Velho ${ }^{2}$ enfatiza e estuda, pelas subculturas.

Cada uma das profissões de saúde reconhecidas pela sociedade brasileira se organiza com suas culturas "de cuidar do outro" no contexto de um sistema de saúdeque, por sua vez, seorganiza a partir de uma regulação dessas culturas associadas à cultura decuidado que seinstitui na sociedade civil e, ainda, no âmbito dos planejadores, gestores e políticos.

Parecem existir pelo menos dois riscos ao se falar "por", quando observamos como as famílias cuidam de seus membros que são usuários de um sistema desaúde público. Primeiro, porqueé desse lugar, onde a prática profissional busca orientar-sesegundo uma racionalidade, quedela saímos também. Ambos, cidadãos usuários e profissionais, conjugamos nossas culturas num ambiente comum, porém em lados diferentes. 0 segundo risco seria o de tentar desconsiderarmos por completo os aspectos de nossa vida privada, que pode estar envolta ou não por práticas místicas ou crenças que nos aproximam ou nos distanciam da vida de nossos sujeitos. Isso significa dizer queé possível que em nósjá existam os conflitos. Adotamos para nós uma prática de cuidados culturalmentedistante daquela que praticamos profissionalmente.

Ao nos referirmos à prática de cuidados marcada pela cultura, destacamos que não falamos de uma cultura como poder, mas como algo ao qual, como diz Geertz ${ }^{5}$, podem ser atribuídos casualmente os acontecimentos sociais, os comportamentos, as instituições ou os processos; ela é um contexto, al go dentro do qual eles podem ser descritos de forma inteligível, isto é, com densidade". 0 desafio passa a ser o de ver as coisas "do ponto de vista do nativo.

0 que o autor quer dizer com o "ver as coisas do ponto de vista do nativo" é que as descrições culturais que fazemos devem ser encaradas em termos das nossas interpretações sobre fenômenos que surgem e se tecem no âmbito das relações humanas. No campo da Saúde Coletiva, podemos considerar que "nativos" são os ou- 
tros, ou seja, os sujeitos como vimos, até então, considerando na prática de nossas investigações acadêmicas: nossos principais interlocutores nas observações participantes, entrevistas, enfim, na prática etnográfica em saúde.

De um ponto de vista epistemológico, isso significa que compreender a cultura de cuidado pelas famílias expõe o que Ihes é "normal" em seu cotidiano e, como pontua Geertz ${ }^{5}$ eem nosso caso, podemos concordar, ver as coisas sob a ótica do sujeito não significa uma redução deuma particularidade de cuidar.

Uma coisa é o olhar para as pessoas em sua teia de relações cotidianas, que é onde o cuidado acontece, e outra é o ol har para o cuidado que praticam que extraímos dessa teia, talvez numa forma bruta, e tentar estudá-lo. No estudo do cuidado praticado pelas famílias na dimensão cultural que tomamos, a análise penetra na vidae no cotidiano dos sujeitos, mas isso não significa que descreveremos a vida deles etoda a sua teia de relações exatamente como são. A linha entre a cultura do cuidado como um fato natural ea cultura do cuidado como entidade teórica tende a ser obscurecida segundo esse viés de pensamento.

Finalmente, ao olharmos para a vida de nossos sujeitos, o que inicialmente fazemos é interpretar. Interpretamos o que dizem sobre si, sobre seu núcleo familiar e sobre parentes. Interpretamoso queachamosquequerem dizer quando não expressam verbalmente o que fazem, ficando nas entrelinhas, ou ainda, no avesso do quetecem. 0 não visível. Interpretamostambém o que achamos que eles pensam e querem para resolver o problema de saúde de seu familiar doente, suas expectativas. Estaremos, enfim, no caso do estudo da vida após uma alta hospitalar, atentos ao comportamento das pessoas que convivem naquele ambiente. Devemos nos atentar "ao comportamento, ecom exatidão, pois éatravés do fluxo do comportamento - ou mais precisamente da ação social - que as formas culturais encontram articulação".

Assim, o significado de "cuidar" para a família vai emergindo do papel que ela desempenha na sociedade contemporânea, com as nuances das subculturas envolvidas. E o padrão de vida que daí decorre, para a população de baixa renda eusuária do Sistema ú nico de Saúde, quase sempre, evidencia um conjunto de desafios frente a uma crescente vulnerabilidade da vida humana aos chamados fatores de risco. As observações etnográficas em cenários dessa natureza, que buscam encontrar "o comum" nas famílias que cuidam (ou tentam cuidar de um membro do- ente), adotando formas não usuais (as da cultura hospitalar, por exemplo) de praticar o cuidado, põem em evidência a arbitrariedade do comportamento humano. 0 seu ir-e-vir com ou sem rotinas estabelecidas.

A vida após a alta: conclusões a partir do estudo etnográfico

Encerrando este artigo, apresentamos algumas considerações sobre o cuidado de saúde após a alta hospitalar, objeto de atenção e estudo cujo processo de investigação discutimos antes, sob o enfoque do pensamento antropológico de Cliford Geertz. Por razões de espaço, não será possível incluir o material empírico que conduziu a essa análise.

Nos momentos que antecedem à saída do hospital, um primeiro enotado esforço de adaptação pela família se inicia. A distância existente entre o hospital ea casa parece estimular respostas humanas à condição de adoecimento ou de agravo que fica a cargo da família. No caminho de volta, evidenciam-se as expressões caracterizadoras de angústia através de falas, fácies, olhares, respirações profundas, permitindo interpretações indicativas de que se inicia um processo rumo à adaptação.

Os primeiros comportamentos indicativos de um modo de cuidar pela família iniciaram-seem resposta de sofrimento, associado a uma angústia que parecia estar relacionada à falta de recursos para o alívio deste. Recursos de diversas naturezas: ambiente adequado, suporte financeiro para aquisição de medicamentos e tecnologias, acesso a serviços, conhecimentos, entre outros. Ao viver momentos de forte tensão emocional, iniciada desdeo surgimento da doença ou agudização de um agravo em um de seus membros, também durante a internação, no momento da alta e após esta, a família empenhada no acolhimento do membro doente desenvolve seus próprios modos de cuidar. Modos de cuidar evidenciados pelas trajetórias de buscas e pedidos de ajuda, seja num entorno microssociológico de convivência, seja no interior do sistema de saúde.

Apreendemos o cuidado desenvolvido pela família após a alta, primeiro, pela observação e reconhecimento deum cotidiano de convivência intrafamiliar. Este se evidenciou através de conflitos entreos membros, quese organizaram para desenvolvêlo ou, ainda, especializando-se, no interior da família a partir de uma redefinição de papéis pelos membros. 
O lidar com uma diversidade de formas de cuidados se institui para além da prioridade de cuidados com o corpo do familiar doente. Aos poucos, a família passa a viver momentos de adaptação a uma situação de ter que cuidar de alguém doente em casa, explicitando situações que parecem rotineiras, como: a dificuldade de exercer os cuidados em casa; as queixas constantes de cansaço com visível esgotamento físico e emocional; os movimentos de busca de ajuda de pessoas e de equipamentos; as redes de aproximações solidárias, principalmente entre os vizinhos, quevinham, às vezes, ajudar em atividades de cuidados, como o banho. Estabiliza-se o potencial de cuidados no ambiente familiar com a demarcação dos papéis de cada um dos membros, visando ao equilíbrio e à manutenção de um "estado de cuidado".

Na relação com a oferta de serviços especializados do SUS, um fenômeno apreendido no momento da alta hospitalar foi um modo de assistir e de cuidar manifestado na forma de desassistência, mas "desassistência" específica à saúde para essa parcela da população. Esta parece estar relacionada ao não encontro deduas concepções de cuidado e de vida. Uma oriunda dos profissionais de saúde, que, no momento, representam a instituição prestadora de serviços de saúde, e, outra, própria do paciente e família.

Observamos, do lado da instituição de saúde, uma despersonificação da pessoa doente e da família no momento da alta ("paciente do leito 8 que teve AVC"). Evidenciou-se uma nuance cultural própria da instituição hospitalar, estabelecida pela prática dos profissionais, ao "devolver" a pessoa dequem momentaneamentecuidou por algum agravo à sua saúde à família, conseqüentemente à sociedade, acreditando ter cumprido "seu papel".

Tece-se, de modo gradativo, uma cultura de instituição que se ocupa em curar ou dar um alívio compatível à vida à medida que assinala num boletim de alta: "melhorado". Aponta para a necessidade do estudo da cultura institucional que pareceestabelecer critérios para "devolver" o "doente" à família.

Noutro fenômeno apreendido no momento da alta hospitalar, "a entrega" do doente ou paciente à família, já se pode notar uma codificação de linguagem que marca a cultura de grupos sociais, orientando o tipo de abordagem que aqui se pretende. $\mathrm{N}$ as observações dos grupos que cuidam em instituições de saúde, que possuem o chamado "saber científico", nota-se uma prática de despersonificação da pessoa que passa a ocu- par um lugar de dependência de cuidados. Do lado do "doente" ou "paciente" e família, nota-se uma perda da autonomia sobre o cuidar de si, além de uma submissão aos saberes técnicos especializados desses profissionais de saúde.

A instituição de saúde "devolve" o "doente" à família. A cultura que se institui em torno da prática assistencial desenvolvida no hospital é a de que esta instituição se ocupa em curar ou dar um alívio compatível à vida, no sentido de estar vivo. Quando o médico assinala "melhorado" no boletim de alta, representando a instituição hospitalar, percebe-se, implícita, uma crença de se ter cumprido "seu papel" ao "devolver" para a família, e conseqüentemente à sociedade, a pessoa, dequem, momentaneamente, secuidou, por algum agravo de sua saúde.

Identificamos, com isso, a existência de um limiar entre os níveis de atenção e cuidados de saúde no interior do Sistema de Saúde, demarcando o compromisso do hospital. Uma nítida ausência de diálogo, como se existisse um muro ou porta imaginária, por onde o paciente efamília atravessam para um ou outro lado, para um ou outro mundo, com uma e outra cultura de cuidados de saúde. Esses níveis ou campos demarcatórios estão coerentes com a diretriz de hierarquização adotada pelo SUS, por vezes, na contramão de uma concepção acerca do princípio da integralidade do cuidado de saúde a que se propõe. Fica-nos uma pergunta. É possível desenvolver ações ou cuidado de saúde integral, com acoIhimento das necessidades do cidadão num modelo (rigidamente) hierarquizado de atenção à saúde, tal como organizado hoje no SUS?

0 que chamamos de desassistência manifestou-se por duas formas: uma proveniente da prática assistencial quesedifunde socialmente, numa cultura denatural ização da terminalidade da vida secundária ao adoecimento crônico, o quese evidenciou pelas expressões: "não tem cura!", "não há mais o que fazer", "agora é ficar com a família". Uma hipótese é que a impossibilidade de recursos de cura estimule certo desânimo em investir no cuidado integral, privando a pessoa de algum grau de qualidade de vida. Outra forma foi a desassistência mesmo, com seu significado de "privado de assistência, amparo, ajuda, desprotegido", que se observa no fluxo da organização da atenção à saúde. Notamos 0 abandono a que essas pessoas estão submetidas no "imenso mundo assistencial", conhecido como atenção secundária ou de média complexidade ambulatorial e hospitalar. 0 sofrimento de busca (às vezes de exaustão pelo ir daqui para lá, retornar...) 
não se configura em objeto de cuidado. A trajetória éincerta após a alta hospitalar, sem um vínculo institucional orientador dos cuidados prioritários de que necessitam.

A idéia de que as pessoas que sofrem algum tipo de agravo e que permanentemente demandam cuidados especializados de profissionais de saúde fiquem sob os cuidados da família remete-nos a uma reflexão sobre o que Estado poderia limitar-sea oferecer, que fica no plano técnico ou do cuidado institucionalizado, direcionado às respostas objetivas de dor, relacionadas, principalmente ao plano do corpo físico ou dos transtornos mentais. Por outro lado, tem também o potencial de cuidar da família, frentea essas condições que não deve ser descartado, o cuidado que culturalmente se espera das famílias na sociedade contemporânea urbanizada ao conviver com um membro doente.

Notamos, na esfera intrafamiliar, o surgimento de uma noção de "grau de dependência para o cuidado". 0 estudo possibilitou-nos uma compreensão do "grau de dependência" para o cuidado de saúde, do ponto de vista da integralidade do cuidado, sob três aspectos: dependência de cuidados clínicos especializados; da prática de cuidados com o corpo realizado pela própria família e, ainda, a dependência das relações extrafamiliares estabelecidas com o sistema de saúde (público ou privado) conforme as necessidades pontuais (consultas, exames, procedimentos).

Com as fragilidades próprias da vida em contextos urbanos, a dependência "quase total" de um sistema decuidados institucionalizados, identificada por este estudo, permitiu uma análise acerca da autonomia para o cuidado e autocuidado, mostrando que existem visões diferentes quando a pessoa se autocuida, que se sente segura e com autonomia permitida pelos vínculos assistenciais institucionais, e quando 0 autocuidado éprescrito num contexto de impossibilidade de ser realizado.

Sobre os processos de vida após uma alta hospitalar, o que finalmente observamos foi que ocorrência deum evento ameaçador à vida coloca em sobressalto os membros da família, sobretudo os adultos que a compõem. A primeira manifestação de uma doença grave ou uma agudização em caso de pessoas portadoras de doenças crônicas representa aflição para ambas as partes: para a família e para aquele que, de fato, vive o problema, em dimensões distintas de valorização e de sentidos da vida.

Observamos o surgimento de uma revisão ou revalorização da vida, que quase sempre vem acompanhada por sentimentos de culpa, medo, frustrações ede sofrimento acerca das limitações. Um sofrimento inicial que leva a pessoa e a família a um equilíbrio num campo de adaptação que passam a assumir como a vida após a alta, que, na verdade, é a vida que se pode ter dali para diante, mas numa adaptação que a própria família encontra e que dificilmente pode ser prescrita. Não é o caso de delimitar o início de uma nova fase na vida sem compreender o que não foi dito, mas o que dele se pode nos enunciar continuamente ao lidar com essas famílias.

Concordamos com Norbert Elias ${ }^{13}$ que, ao estudar a relação do ser humano com a morte ou eminência desta ao longo de momentos históricos e na sociedade contemporânea, expressa o pensamento de que, mediante as ameaças à vida humana, em quaisquer circunstâncias, há uma busca de adaptação pelo homem à vida comum. Para Elias'13, o buscar adaptar-se ao "comum" ou, como diria Bourdieu14, a uma "norma universal", se expressa através da formação de grupos, como, por exemplo, a família.

Antes, então, de falar em adaptação, atentase à dinâmica das famílias após o adoecimento grave de um familiar e em momentos variados. O momento após uma alta hospitalar em que receberam tratamentos complexos, as formas obscurecidas e de lidar ou enfrentar a situação inédita se evidenciam de um modo agudo e desordenado. Conflitos de diversas naturezas surgem e a relação delas com seu corpo e sua inserção social e com o sistema de saúde se mostra vulnerável. É possível queuma experiência prévia na lida com o adoecimento contribua para esse lidar atual, todavia não é uma regra que se pode generalizar.

$\mathrm{Na}$ sociedade contemporânea, as respostas dos membros da família parecem estar coerentes com o que se publica a partir do progresso da ciência médica. 0 lidar com o processo saúdedoença, considerando uma agudização que prenuncia um "estágio final", cobra uma maturidade para convivência com um "processo natural". Elias ${ }^{19}$ ressalta que "a idéia de um processo natural ordenado é característica de um estágio específico no desenvolvimento do conhecimento eda sociedade". Podemos concordar que essa concepção da natureza está estabelecida nas sociedades desenvolvidas. Parece existir uma confiança inabalável nas leis da natureza, nas ciências naturais, que contribui com uma sensação de segurança diante de fatos naturais.

$\mathrm{N}$ a sociedade brasileira, todavia, notamos que vivemos uma fase intermediária em termos da 
busca para um lidar com o sofrimento, tendo em vista o desamparo em relação à oferta de tecnologias de cuidado. 0 sofrimento se evidencia, como que sob uma lente de aumento. 0 não ter à mão uma resposta de alívio leva as pessoas a adentrarem-se num processo de busca de alternativas dentro do seu próprio leque de conhecimentos e de convivência.

Em sociedades consideradas mais desenvolvidas e também na nossa, podemos concordar queapenas as rotinas institucionalizadas dos hospitais dão alguma estruturação social para a situação de "morrer", como diria Elias ${ }^{13}$, e acrescentamos para o "salvar da morte", para permiti-lo, pelo menos "estar vivo". 0 que está por detrás do perambular no interior do sistema de saúde, ou fora dele, em busca de respostas de alívio ou de remissão total do problema de saúde é a busca pelo prolongamento da vidae, portanto, uma luta contra o fato natural da proximidade da morte, que parece ser o pano de fundo ameaçador.

Elias ${ }^{13}$ localiza a família como sendo a instituição social privilegiada ao enfrentamento e à convivência com os problemas decorrentes da velhice e da doença, nas sociedades préindus- triais ou que convivem em pequenas cidades, próximas do campo ou nele. Já nas sociedades industriais e urbanizadas, tal enfrentamento se dá muito mais publicamente, mas dentro do domínio da família. Interessante destacar algo que já estamosenfatizando neste trabalho: o fato de que 0 acolhimento dessas pessoas fica a cargo da família e de que elas podem experimentar ou não um tratamento amável. Na concepção de Elias , "não faz parte das tarefas do Estado imiscuir-se nesses assuntos".

Contudo, as "buscas de cuidado vs a necessidade atendida", ou o número de tentativas de buscas e o "conseguir" ou o "não conseguir" e 0 acesso ao cuidado desejado fora do ambiente intrafamiliar foram situações apreendidas como rotina marcante, na relação dessas famílias com - Sistema de Saúde. Nem semprea oferta de serviços na rede assistencial permitia 0 acesso, com resolução ou satisfação das necessidades de cuidados de saúde das famílias acompanhadas.

O "voltar para casa", tecido pelo paciente e família, pôs-seà mostra como um longo etortuoso caminho, considerando a ausência ou dificuldade intensa de acesso aos cuidados especializados.

\section{Colaboradores}

K R Camargo-Junior orientou a concepção, a pesquisa, a metodologia e contribuiu na estruturação do artigo e na redação final; EAB de Castro desenvolveu a concepção, a pesquisa, a metodologia, a organização do artigo e a redação final. 


\section{Referências}

1. Castro EAB. A vida após a alta [tese]. Rio de Janeiro (RJ): Universidade Estadual do Rio de Janeiro; 2005.

2. Certeau M. A cultura no plural. 2a ed. São Paulo: Papirus/Travessia do Século; 2001.

3. Pinheiro R, Mattos R, organizadores. Os sentidos da integralidade: na atenção e no cuidado à saúde. Rio de Janeiro: IM S/UERJ-ABRASC 0; 2001.

4. Bonet O. Saber e sentir: uma etnografia da aprendizagem da biomedicina. Rio de Janeiro: Fiocruz; 2004

5. Geertz C. A interpretação das culturas. Rio de Janeiro: Guanabara Koogan; 1989.

6. Geertz C. Nova luz sobre a Antropologia. Rio de Janeiro: Jorge Zahar; 2001.

7. Geertz C. O bras e vidas: 0 antropólogo como autor. Rio de Janeiro: Ed. da UFRJ; 2002.

8. Geertz C. 0 saber local: novos ensaios em antropologia interpretativa. 3a ed. Petrópolis: Vozes; 2000.

9. Leininger $M$. Teoria de enfermagem transcultural. In: George J. Teorias de Enfermagem: os fundamentos para a prática profissional. Porto Alegre: Artes M édicas; 1993. p. 285-299.

10. Clifford J. Experiência etnográfica: antropologia e literatura no século XX. In: Gonçalves JRS, organizador. A experiência etnográfica: antropologia e literatura no século XX. Rio de Janeiro: Ed. da UFRJ; 1998.

11. M erleau-Ponty M. A prosa do mundo. São Paulo: Cosac \& Naify; 2002.

12. Velho G. Individualismo e cultura: notas para uma antropologia da sociedade contemporânea. $7 \underline{a}$ ed. Rio de Janeiro: Jorge Zahar; 2004.

13. Elias N. A solidão dos moribundos: seguido de enveIhecer e morrer. Rio de Janeiro : Jorge Zahar; 2001.

14. Bourdieu P. Razões e práticas: sobre a teoria da ação. 3a ed. Campinas: Papirus; 2001

Artigo apresentado em 28/08/2006

Aprovado em 02/03/2007

Versão final apresentada em 15/06/2007 